\title{
ÁLCOOIS QUIRAIS: MÉTODOS QUÍMICOS E CATALÍTICOS DE OBTENÇÃo POR REDUÇÃO ASSIMÉTRICA
}

\section{Eliane Silvia Codo Temba, Ione Maria Ferreira de Oliveira e Claudio Luis Donnici*}

Departamento de Química, Instituto de Ciências Exatas, Universidade Federal de Minas Gerais, CP 702, 31270-901

Belo Horizonte - MG

Recebido em 13/2/02; aceito em 17/4/02

\begin{abstract}
CHIRAL ALCOHOLS: CHEMICAL AND CATALYTIC METHODS OF PREPARATION BY ASYMMETRIC REDUCTION. The importance of chiral alcohols as starting materials for the production of fine chemicals and as useful chirons for the building of several interesting molecules or natural products is reported. The useful and common methods of asymmetric reduction such as the chemical (with organoboron or organoaluminum reagents) and the catalytic ones (with ruthenium or rhodium complexes) for preparation of chiral alcohols are described; even the newer and much more rare electrocatalytic methods are reported.
\end{abstract}

Keywords: chiral alcohols; asymmetric reduction; catalysis and electrocatalysis.

\section{INTRODUÇÃO}

Nos últimos anos, os avanços em síntese orgânica vêm possibilitando a preparação, por síntese total, de muitos compostos especialmente úteis devido às suas propriedades biológicas. Dentre estes podem-se destacar os compostos quirais, que possuem átomos ditos assimétricos ou dissimétricos e que existem na forma de enantiômeros. A preparação seletiva destes enantiômeros através do método de síntese enantiosseletiva é importante pois, cada um deles, pode apresentar propriedades físico-químicas e biológicas distintas ${ }^{1}$. Apesar dos compostos quirais serem comuns na natureza são necessários métodos específicos de síntese para sua obtenção artificial, dentro da área conhecida como síntese assimétrical. O termo "síntese assimétrica" foi criado por Marckwald², em 1904, e imediatamente adotado. Apesar da sua breve história ${ }^{2}$, desde aquela época a sua importância é indiscutível e a obtenção sintética de substâncias enantiomericamente puras (SEP) ainda é uma fronteira que está a ser ultrapassada ${ }^{3}$.

$\mathrm{O}$ aspecto mais importante para a obtenção destes compostos quirais é o controle estereoquímico, essencial para uma boa síntese enantiosseletiva e que possui uma influência nas considerações estratégicas, incluindo a escolha de uma rota em particular. A eficiência da síntese assimétrica, ou o grau de seletividade na obtenção preferencial de um dos enantiômeros, é geralmente avaliada em termos de excesso enantiomérico (e.e.), definido por $(R-S) /(R+S) x$ 100 , onde R e $\mathrm{S}$ são as quantidades relativas dos enantiômeros $\mathrm{R}$ e $\mathrm{S}^{1,4}$.

A partir da década de 70, a síntese assimétrica ganhou destaque como método de obtenção de compostos enantiomericamente puros, em substituição à resolução de racematos, pois este método possibilita a criação de novos centros quirais durante as etapas de síntese proporcionando a preparação de substâncias enantiomericamente puras, através da obtenção exclusiva ou preferencial de um estereoisômero, sendo uma das mais importantes áreas da síntese orgânica contemporânea ${ }^{1,3,4}$. De fato, nesta área os álcoois quirais merecem destaque como precursores quirais e como auxiliares de quiralidade.

\section{ÁLCOOIS QUIRAIS: IMPORTÂNCIA}

Apesar de não serem geralmente muito conhecidos como os precursores quirais naturais usuais, os álcoois quirais são também precursores importantes, que podem servir como intermediários ou como blocos de construção quirais ("chiral building blocks") 3 na síntese de diversos compostos quirais de importância biológica (Figura 1). Entre vários exemplos, o (S)-(-)-3-hidróxi-butanoato de etila (1), oticamente ativo, é um dos álcoois quirais mais utilizados como precursor quiral em síntese orgânica: o (S)-(+)-sulcatol ${ }^{5}(2)$, importante insumo para a síntese de outros produtos naturais ${ }^{5}$; (R)-lavandulol ${ }^{6}$ (3), importante aditivo na indústria de perfumes; (R)-(+)-recifeiolídeo ${ }^{7}$ (4), macrolídeo natural isolado do Cephalosporum recifei $i^{7}$; (R,R)-(-)grahamimicina ${ }^{8}(\mathbf{5})$, macrodiolídeo de atividade antibiótica reconhecida $^{8} ;(\mathrm{R}, \mathrm{R})$-pirenoforina ${ }^{9}(\mathbf{6})$, um diolídeo representativo de ocorrência natural com atividade fungicida a partir de sulcatol $2^{5}$ e a
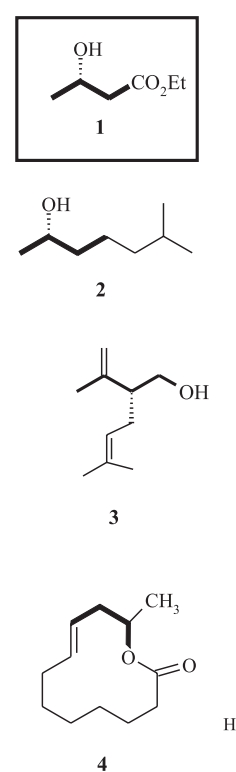

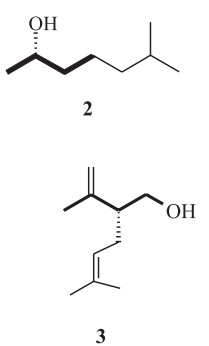

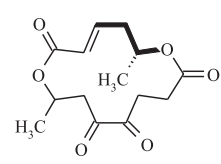

5
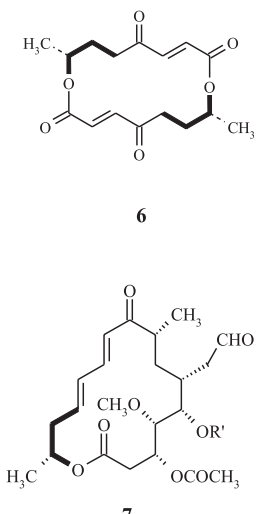
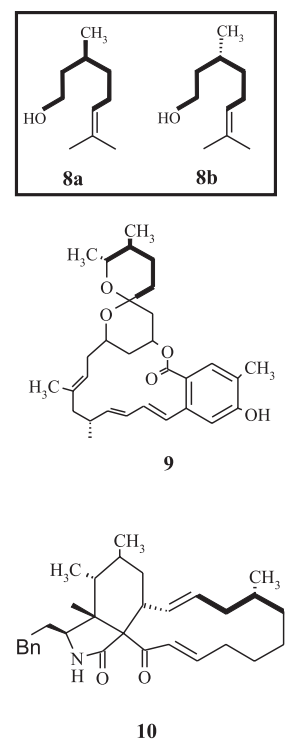

Figura 1. Produtos naturais obtidos a partir dos álcoois quirais, (R)- ou (S)-3-hidroxibutanoato de etila (1) e (R)-(8a) ou (S)-citronelol (8b) 
carbomicina $\mathrm{B}^{10}(7)$, um outro antibiótico macrolídeo. Os terpenos ${ }^{11}$ incluem álcoois e derivados de grande importância em síntese orgânica, quer como precursores, quer como auxiliares quirais, sendo vários de origem natural. Existem exemplos destacáveis de síntese total partindo-se de terpenóis: a síntese da milbemicina $\beta_{3}(\mathbf{9})$ a partir do $(\mathrm{S})-(-)$-citronelol $^{12}(\mathbf{8 a})$ e a síntese de proxifomina $(\mathbf{1 0})$ a partir do $(\mathrm{R})-(+)$-citronelol $(\mathbf{8 b})^{13}$.

O mentol é um outro terpeno quiral também muito usado como insumo, natural ou sintético, tendo a sua grande aplicação como aromatizante pelo efeito refrescante, tão apreciado ${ }^{14}$, apenas do enantiômero levógiro, o (1R,2S,5R)-(-)-5-metil-2-(1-metiletil)- ciclo-hexanol, ou (1R,2S,5R)-(-)-mentol (11). Além disso, o mentol tem amplo uso como auxiliar de quiralidade e várias outras aplicações sintéticas ${ }^{11,15}$. Cabe lembrar que vários feromônios ${ }^{16}$ de interesse são também álcoois quirais como o sulcatol 2, que tem sido muito estudado como feromônio de besouro Gnathotrichus sulcatus e Gnathotrichus retusus ${ }^{5}$ e outros vários, como os exemplos de 12 a 16 (Figura 2) que também foram sintetizados por vários métodos clássicos, de complexidade variável, envolvendo $\alpha$-aminoácidos, carboidratos e terpenos ${ }^{16}$ como material de partida. Um exemplo de álcool quiral ainda mais notável é o 1-octen-3-ol (17) que é ferômonio importante na atração de mosquitos ${ }^{17}$, tendo chamado muito a atenção de pesquisadores em todo o mundo e no Brasil ${ }^{18}$.<smiles>CC1CCC(O)C(C(C)C)C1</smiles><smiles>CC1=CC(O)CCC1</smiles>

12

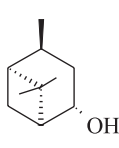

13

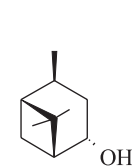

14

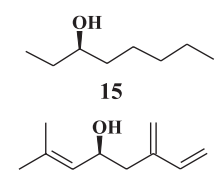

16

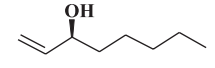

17
Figura 2. Estrutura de alguns álcoois quirais de interesse

Contudo, apesar da importância de tais álcoois quirais e de tantos outros, ainda não são muitas as rotas práticas para a sua obtenção ${ }^{19}$ e não há artigos de divulgação ou revisão que tratem amplamente de métodos químicos para preparação de álcoois quirais e de sua aplicação sintética. Uma exceção é o artigo de revisão de Singh, de 1992, que trata exclusivamente de métodos de redução enantiosseletiva de cetonas não-simétricas, sem enfatizar as aplicações dos álcoois quirais em síntese orgânica ${ }^{19}$.

\section{ÁLCOOIS QUIRAIS: MÉTODOS DE OBTENÇÃO}

Apesar da preparação de álcoois quirais poder ser efetuada por vias sintéticas complexas ${ }^{1,4,11,19}$, a sua obtenção pode ser feita de modo mais simples e prático pela reação de um composto carbonílico próquiral $\mathrm{R}_{1} \mathrm{COR}_{2}$ com um agente redutor quiral ( $\mathrm{R}^{*}$ )- (Figura 3). Tal reação deve originar indução assimétrica, visto que as duas faces (re e si) do plano das cetonas pró-quirais são enantiotópicas ${ }^{1}$ e, no estado de transição, devem formar intermediários diastereotópicos (Figura 3) conduzindo, finalmente, à obtenção preferencial de um dos enantiômeros.

Dentre os diversos reagentes quirais existentes para a obtenção de álcoois quirais a partir de cetonas pró-quirais destacam-se os relatados a seguir.
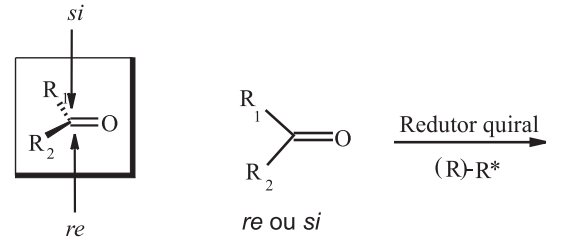<smiles>[R]C([R])([R])O</smiles>

substrato pró-quiral<smiles>[R]C([R])([R])O</smiles>

$\left(\mathrm{R}^{*}, \mathrm{R}\right)$

Figura 3. Redução quiral de cetona pró-quiral gerando par diastereoisomérico de álcoois

\section{Obtenção de álcoois quirais por uso de redutores quirais de alumínio e boro}

A utilização de hidretos de boro e de alumínio para redução de compostos carbonílicos é muito comum em síntese orgânica e o desenvolvimento das versões quirais eficientes destes hidretos tem ocupado uma posição central nas últimas décadas.

Muito desse esforço foi concentrado no hidreto de lítio e alumínio, modificado pela adição de ligantes quirais, incluindo dióis, aminas, diaminas, aminocarbinóis e diaminocarbinóis ${ }^{1,20}$, sendo que a obtenção de níveis razoáveis de enantiosseletividade tem sido limitada pelo pequeno número de estruturas do substrato (aril-alquilcetonas e cetonas acetilênicas), particularmente devido ao processo concorrente de desproporcionamento pelo uso de $\mathrm{LiAl}(\mathrm{OR} *)_{3}$.

Dentre os derivados de organo-alumínio utilizados, o derivado binaftílico conhecido como BINAL-H (redutor assimétrico formado in situ pela reação do auxiliar quiral 1,1'-bis-2,2'-naftol (R)- ou (S)-, ambos comerciais, com hidreto de lítio e alumínio em álcool metílico ou etílico) é de destaque (Figura 4), fornecendo excelentes resultados de 95-100\% de excesso enantiomérico ${ }^{20}$. Observou-se que a presença de um modificador secundário (metanol ou etanol) é importante pois, na redução de acetofenona sem etanol, somente $2 \%$ de e.e. é obtido. A utilização de álcoois volumosos leva à inversão da indução assimétrica.
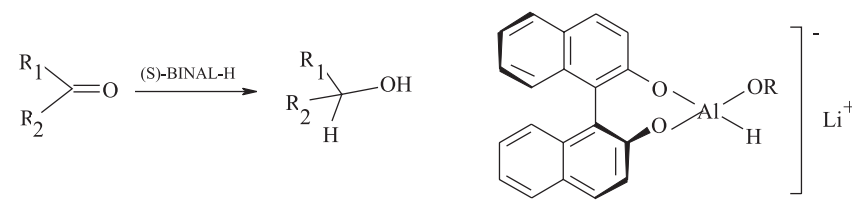

(S)-BINAL-H

$$
\mathrm{R}=\mathrm{CH}_{3}, \mathrm{Et}
$$

Figura 4. Uso de BINAL- H como redutor quiral

Alguns exemplos da redução com (S)-BINAL-H para uma série de compostos carbonílicos estão sumarizados na Tabela $1^{20}$.

Tabela 1. Excessos enantioméricos (e.e.) obtidos da redução de cetonas $\mathrm{R}^{1} \mathrm{R}^{2} \mathrm{C}=\mathrm{O}$ com (S)-BINAL-H alcóxi substituído

\begin{tabular}{cccc}
\hline $\mathrm{R}^{1}$ & $\mathrm{R}^{2}$ & $\mathrm{R}$ & e.e. $(\%)$ \\
\hline $\mathrm{C}_{6} \mathrm{H}_{5}$ & $\mathrm{CH}_{3}$ & $\mathrm{Et}$ & 95 \\
$\mathrm{C}_{6} \mathrm{H}_{5}$ & $\mathrm{Et}$ & $\mathrm{Et}$ & 98 \\
$\mathrm{C}_{6} \mathrm{H}_{5}$ & $\mathrm{Pr}$ & $\mathrm{Et}$ & 100 \\
$\mathrm{C}_{6} \mathrm{H}_{5}$ & $\mathrm{iPr}$ & $\mathrm{Et}$ & 71 \\
$\mathrm{n}-\mathrm{BuC} \equiv \mathrm{C}$ & $\mathrm{CH}_{3}$ & $\mathrm{Me}$ & 84 \\
$\mathrm{n}-\mathrm{BuC} \equiv \mathrm{C}$ & $\mathrm{n}^{-\mathrm{C}_{5} \mathrm{H}_{11}}$ & $\mathrm{Me}$ & 90 \\
\hline
\end{tabular}


Os resultados estereoquímicos foram racionalizados considerando-se quatro estruturas para os estados de transição (A-D), Figura $5^{1,20}$.
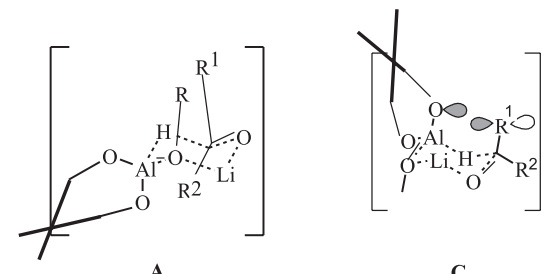

C

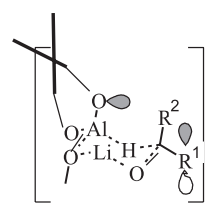

D
$\mathbf{B}=\mathbf{A}, \operatorname{com} \mathrm{R}^{1}$ e $\mathrm{R}^{2}$ trocados de posição

Figura 5. Estados de transição sugeridos para a redução de cetonas com (S)-BINAL-H

As estruturas A e B, propostas como estados de transição, foram rejeitadas pelas fortes interações entre o grupo alquila $\mathrm{R}$ e um dos átomos de hidrogênio do anel binaftila. A estrutura $\mathbf{C}$ também não deve ser considerada devido à repulsão entre o orbital não-ligante do oxigênio e o orbital $\pi$ do substituinte $\mathrm{R}$ axial. Assim, a reação deve ocorrer via estado de transição com a estrutura D gerando o (S)carbinol. A interação 1,3-diaxial favorecerá a posição do substituinte mais volumoso $\mathrm{L}$ em equatorial e o menos volumoso $\mathrm{S}$ em axial ${ }^{1,21}$. A influência de fatores estéricos na estereosseletividade destas reduções pode ser comprovadamente evidenciada no caso da redução de cetonas alquil-acetilênicas, onde se observa que o aumento do volume e do impedimento estérico do grupo alquila tem um efeito de anulação na diferenciação enantiofacial, e a redução de etinilisopropil-cetona decresce de $84-94 \%$ e.e. para somente $57 \%$ e.e..$^{21,22}$ (Tabela 2). Estes exemplos são também ilustrativos por demonstrarem a possível obtenção dos dois álcoois enantioméricos diferentes pelo uso de BINAL-H (S)- ou (R)- ${ }^{21}$.

Tabela 2. Excessos enantioméricos (e.e.) obtidos da redução de cetonas acetilênicas $\mathrm{HC} \equiv \mathrm{C}\left(\mathrm{R}_{1}\right) \mathrm{C}=\mathrm{O}$ com ( $\mathrm{S}$ - ou (R)-BINAL-H alcóxi-substituído (OR) ${ }^{21}$

\begin{tabular}{ccccc}
\hline \multicolumn{1}{c}{$\mathrm{R}^{1}$} & OR & BINAL-H & Rend $(\%)$ & e.e. (\%)- config. \\
\hline $\mathrm{n}-\mathrm{C}_{5} \mathrm{H}_{11}$ & $\mathrm{Me}$ & $(\mathrm{S})-$ & 87 & $84(\mathrm{~S})$ \\
$\mathrm{n}-\mathrm{C}_{5} \mathrm{H}_{11}$ & $\mathrm{Et}$ & $(\mathrm{S})-$ & 71 & $84(\mathrm{~S})$ \\
$\mathrm{n}-\mathrm{C}_{8} \mathrm{H}_{17}$ & $\mathrm{Me}$ & $(\mathrm{R})-$ & 69 & $94(\mathrm{R})$ \\
$\mathrm{n}^{-} \mathrm{C}_{8} \mathrm{H}_{17}$ & $\mathrm{Et}$ & $(\mathrm{S})-$ & 74 & $90(\mathrm{~S})$ \\
$\mathrm{n}-\mathrm{C}_{11} \mathrm{H}_{23}$ & $\mathrm{Me}$ & $(\mathrm{S})-$ & 90 & $92(\mathrm{~S})$ \\
${ }_{\mathrm{iPr}}$ & $\mathrm{Me}$ & $(\mathrm{S})-$ & 84 & $57(\mathrm{~S})$ \\
\hline
\end{tabular}

Exemplos sintéticos de interesse com o uso de (S)-BINAL-H são a redução da $\beta$-ionona ao álcool quiral de configuração definida 18 (Figura 6), com quase $100 \%$ e.e. ${ }^{22}$, e a redução de ciclopentenodiona, com $94 \%$ e.e., que gera a 4-hidróxi-2-ciclopenten-1-ona (19), um núcleo chave na síntese de componentes de prostaglandinas ${ }^{23}$ (Figura 6). Recentemente, pode-se destacar a síntese do ácido (S)coriólico $^{24}(\mathbf{2 0})$, importante metabólito do ácido linoléico em plantas e animais com interessantes atividades biológicas, que tem como etapa-chave ( $94 \%$ e.e.) a obtenção do álcool quiral pelo uso de (S)BINAL-H (Figura 6).

Outra classe de reagentes quirais muito empregada para a obtenção de álcoois quirais é a dos organoboranos, principalmente na forma de agentes oticamente ativos formados a partir de terpenos. Dentre os terpenos mais usados destacam-se, particularmente sendo o $\alpha$ -<smiles>CC(O)C=CC1=CCCCC1(C)C</smiles>

18

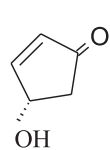

19

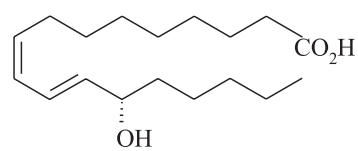

20
Figura 6. Álcoois quirais obtidos da redução de $\beta$-ionona e de ciclopentenodiona, com (S)-BINAL-H e ácido coriólico (20)

pineno (21) o mais abundante e o mais usado como insumo para geração de organoboranos quirais ${ }^{25}$ (Figura 7).

A possibilidade da síntese fácil de organoboranos oticamente ativos para hidroboração de terpenos quirais adequados, como o $1 \mathrm{R}(+)$ - $\alpha$-pineno (21), tem levado muitos pesquisadores, especialmente Brown e Ramachandran ${ }^{25,26}$, ao estudo amplo e à obtenção frequiente de excelentes resultados através da redução assimétrica de cetonas pró-quirais com organoboranos e boroidretos quirais derivados de tais organoboranos. Apesar da descrição anterior dos hidretos de boro, como o Ipc 2 BH e IpcBH $(\mathrm{Ipc}=$ diisopinocanfeila, preparado a partir do $\alpha$-pineno), estes não se mostraram agentes redutores quirais eficientes para cetonas pró-quirais ${ }^{27}$. As estruturas dos organoboranos quirais, derivados do pineno 21, mais comumente usados 22, 23, 24 e 25 são mostradas na Figura 8. É digno de nota que estes organoboranos também têm sido descritos para reações de hidroboração assimétrica com bons resultados ${ }^{26}$.

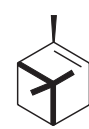

21

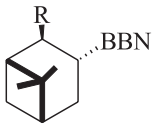

$22 \mathrm{R}=\mathrm{Me}$, Alpino-borano $23 \mathrm{R}=\mathrm{Et}$, Eapino-borano

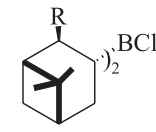

$24 \mathrm{R}=\mathrm{Me}, \mathrm{Ip}_{2} \mathrm{BCl}$ $25 \mathrm{R}=\mathrm{Et}, \mathrm{Eap}_{2} \mathrm{BCl}$
Figura 7. Organoboranos quirais, derivados do pineno

O primeiro agente redutor quiral bem sucedido foi o alpinoborano 22 (Alpine-borane, Aldrich ${ }^{\circledR}$ ) ou $B$-isopinocanfeil-9borabiciclo [3.3.1] nonano; 9-BBN: 9-borabiciclo [3.3.1] nonano utilizado por Midland e colaboradores ${ }^{28}$ para preparar uma série de álcoois pela redução de aldeídos deuterados, RCDO (Esquema 1), em forma enantiomérica pura, e de cetonas aromáticas e acetilênicas. $\mathrm{O}$ auxiliar quiral é recuperado prontamente da mistura reacional ${ }^{29} \mathrm{e}$ cabe ressaltar que este organoborano é um reagente quimiosseletivo que, por exemplo, pode reduzir seletivamente um aldeído na presença de uma cetona, ou reduzir uma cetona acetilênica em presença de uma cetona comum $^{29}$ (Esquema 1). O estado de transição tipo bote

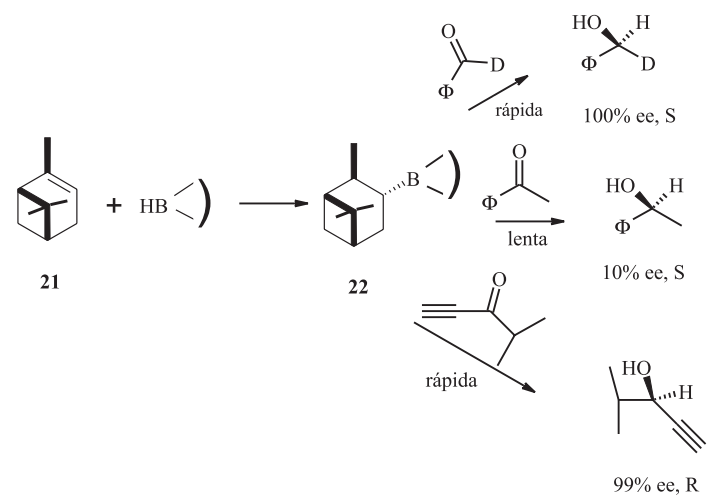

Esquema 1. Exemplos de redução de aldeídos deuterados 
tem sido usado como justificativa para a enantiosseletividade ${ }^{30}$ mas, estudos semi-empíricos mais recentes têm contestado esta proposta de estado de transição ${ }^{31}$.

Apesar dos excelentes resultados na redução de cetonas funcionalizadas, estes organoboranos apresentam baixa seletividade na redução de cetonas simples, o que pode ser explicado pela ocorrência de desidroboração concorrente do reagente em reduções lentas. Entretanto, dentre as aplicações de $\mathbf{2 3} \mathrm{em}$ síntese total (Esquema 2) deve-se destacar a obtenção do japanoluro (26) (hormônio de besouro $)^{32}$ e do intermediário corticosteróide $27^{34}$.
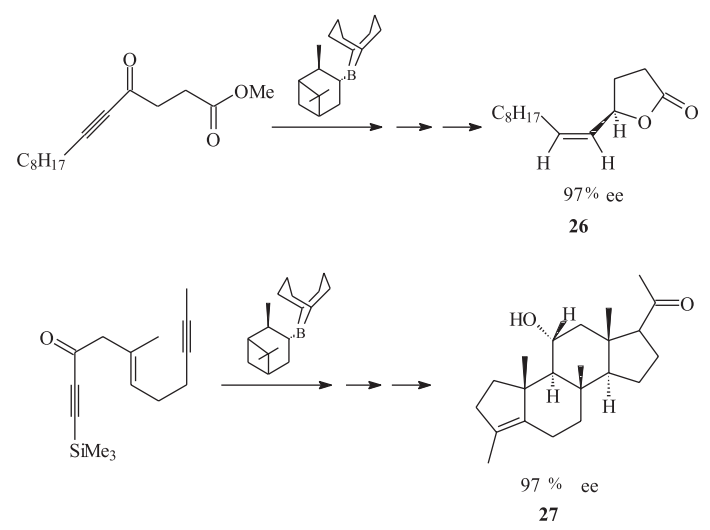

Esquema 2. Redução assimétrica nas sínteses de japanoluro (26) e de intermediário corticosteróide 27

Posteriormente, com o intuito de aumentar a velocidade de redução, descobriram-se os derivados de B-clorodiisopinocanfeil-boranos, tipo $\mathrm{R}_{2} \mathrm{BCl}^{35}$ (Aldrich: DIP-chloride ${ }^{\circledR}$ ) estericamente impedidos, que são mais estáveis frente à dissociação que os trialquilboranos, $\mathrm{R}_{3} \mathrm{~B}$. $\mathrm{O} B$-clorodiisopinocanfeilborano ( $\left.\mathrm{Ipc}_{2} \mathrm{BCl}, 24\right)$ mostrou ser bastante eficiente na redução de aril-alquil-cetonas (Esquema 3) e outras espécies de compostos carbonílicos levando a altos excessos enantioméricos $(>95 \%)^{26}$.

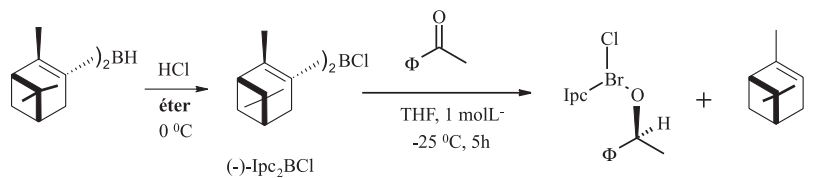

$$
\begin{aligned}
& 24
\end{aligned}
$$

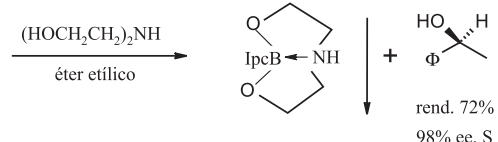

Esquema 3. Redução de aril-alquil-cetonas $\operatorname{com~Ipc~}_{2} \mathrm{BCl}$ (24)

$\mathrm{O} \mathrm{Ipc}_{2} \mathrm{BCl}$ (24) tem muitas aplicações sintéticas onde a redução de arilalquil-cetonas é etapa chave, como na preparação do princípio ativo do medicamento PROZAC (28) ${ }^{36}$, Esquema 4. Diversas outras aplicações do organoborano $\mathbf{2 4}$ em síntese total são notórias, como a redução de cetonas estericamente impedidas $\alpha, \beta$-acetilênicas com e.e excelentes (de 96 a 99\%) ) $^{25}$ e outros exemplos que podem ser encontrados na literatura, como relatado por Brown em artigo de revisão ${ }^{26}$.

Apesar do eapino-borano 23 ( $B$-iso-2-etil-apopinocanfeil-9borabiciclo-[3.3.1] nonano) ser preparado de forma similar ${ }^{38}$ à preparação do análogo metílico, alpino-borano 22, o organoborano 23 é utilizado para redução como o correspondente hidreto $\mathbf{3 0}$, formado

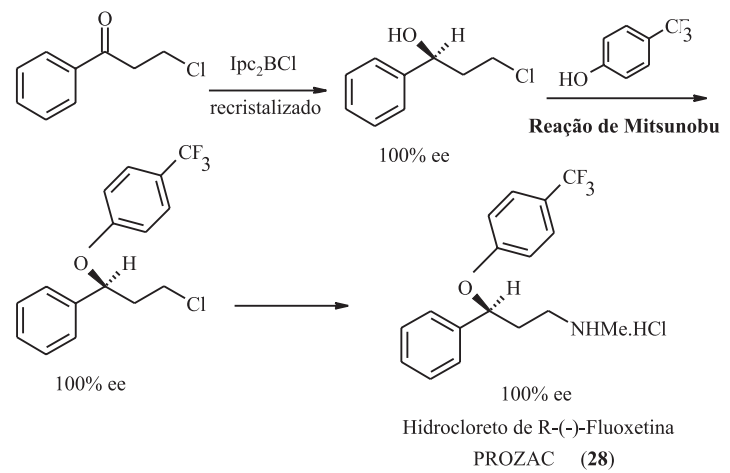

Esquema 4. Síntese do PROZAC (28) usando-se Ipc $\mathrm{BCl}_{2}$ (24)

pela adição de tert-butil lítio, o que também foi feito para o derivado análogo, o alpino-borano 22 que gera o hidreto 29 (Esquema 5). Ambos os hidretos foram testados na redução de cetonas acetilênicas, com o derivado $\mathbf{3 0}$ mostrando resultados melhores que aqueles com o uso de alpino-borano ${ }^{37-39}$ (Tabela 3) .

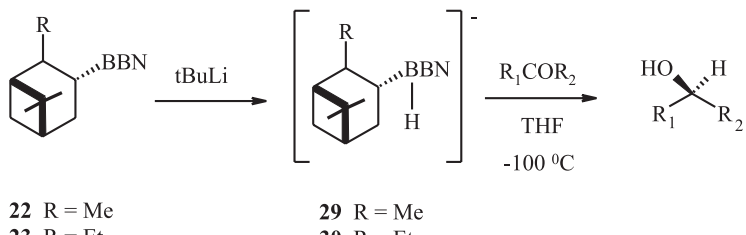

Esquema 5. Obtenção dos hidretos 29 e 30 e seu uso como redutores quirais

Tabela 3. Dados comparativos da redução assimétrica de cetonas por 29 e 30

\begin{tabular}{cccc}
\hline $\mathrm{R}^{1}$ & $\mathrm{R}^{2}$ & 29 e.e. $(\%)$ & 30 e.e. $(\%)$ \\
\hline $\mathrm{HC} \equiv \mathrm{C}^{\mathrm{a}}$ & $\mathrm{Me}$ & 77 & 82 \\
$\mathrm{HC} \equiv \mathrm{C}^{\mathrm{a}}$ & $\mathrm{n}-\mathrm{C}_{5} \mathrm{H}_{11}$ & 88 & 96 \\
$\mathrm{Me}_{2} \mathrm{CHC} \equiv \mathrm{C}^{\mathrm{a}}$ & $\mathrm{Me}$ & 88 & 88 \\
$\mathrm{C}_{6} \mathrm{H}_{5} \mathrm{C} \equiv \mathrm{C}^{\mathrm{a}}$ & $\mathrm{Me}$ & 82 & 89 \\
$\mathrm{n}^{-} \mathrm{C}_{6} \mathrm{H}_{13}$ & $\mathrm{Me}$ & $33^{\mathrm{b}}$ & $77^{\mathrm{c}}$ \\
$\mathrm{c}-\mathrm{C}_{6} \mathrm{H}_{11}$ & $\mathrm{Me}$ & $27^{\mathrm{b}}$ & $80^{\mathrm{c}}$ \\
$\mathrm{C}_{6} \mathrm{H}_{5}$ & $\mathrm{Me}$ & $20^{\mathrm{b}}$ & $61^{\mathrm{c}}$ \\
\hline
\end{tabular}

a) $25^{\circ} \mathrm{C} ;$ b) $-78^{\circ} \mathrm{C} ;$ c) $-100{ }^{\circ} \mathrm{C}$

Em 1991, Brown e colaboradores divulgaram os melhores resultados já obtidos para a redução quiral de cetonas por um derivado organoborado, o Eap $2 \mathrm{BCl}$ (25) (B-clorodiiso-2-etil-aponinocanfeilborano) preparado de acordo com o Esquema $6^{40}$. Os dados da Tabela 4 ilustram a alta eficiência na redução assimétrica de cetonas pelo uso de $\mathrm{Eap}_{2} \mathrm{BCl}^{26,40,41}$ comparativamente ao derivado $\mathrm{Ip}_{2} \mathrm{BCl}(\mathbf{2 4})$. Cabe aqui destacar o artigo de Brown e colaboradores ${ }^{41}$ que apresenta uma visão crítica da eficiência relativa de diversos agentes redutores com diferentes classes de cetonas. É digno de nota que se pode obter bons resultados de enantiosseletividade na redução de cetonas diversas com organoboranos ${ }^{29}$, contudo, deve se ressaltar a importância da presença de grupos fenílicos, vinílicos ou acetilênicos para a obtenção de bons excessos enantioméricos na redução com organoboranos, devido a efeitos estéricos no estado de transição ${ }^{29,41}$.

Itsuno e colaboradores ${ }^{42,43}$ desenvolveram um borano redutor derivado do (S)-2-amino-3-metil-1,1-difenilbutan-1-ol (31) (Figura 8), que gera alta enantiosseletividade na redução de cetonas $(95 \%$ de 


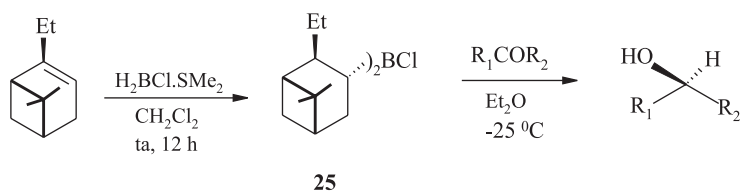

Esquema 6. Preparação do $\mathrm{Eap}_{2} \mathrm{BCl}(25)$

Tabela 4. Dados comparativos da redução assimétrica de cetonas por 24 e 25

\begin{tabular}{cccc}
\hline $\mathrm{R}^{1}$ & $\mathrm{R}^{2}$ & $\begin{array}{c}\mathrm{Ipc}_{2} \mathrm{BCl} \\
(\mathbf{2 4}) \text { e.e.., } \% \\
\text { (config. abs.) }\end{array}$ & $\begin{array}{c}\mathrm{Eap}_{2} \mathrm{BCl} \\
(\mathbf{2 5}) \text { e.e.., } \% \\
\text { (config. abs.) }\end{array}$ \\
\hline${ }_{\mathrm{iPr}}$ & $\mathrm{Me}$ & $32(\mathrm{~S})$ & $95(\mathrm{~S})$ \\
$\mathrm{c}_{\mathrm{C}} \mathrm{C}_{6} \mathrm{H}_{11}$ & $\mathrm{Me}$ & $26(\mathrm{~S})$ & $97(\mathrm{~S})$ \\
$\mathrm{Me}$ & $\mathrm{Py}$ & $92(\mathrm{~S})$ & $\geq 99(\mathrm{~S})$ \\
$\mathrm{C}_{6} \mathrm{H}_{5}$ & $\mathrm{CH}_{2} \mathrm{Cl}$ & $96(\mathrm{R})$ & $\geq 99(\mathrm{R})$ \\
$\mathrm{C}_{6} \mathrm{H}_{5}$ & $\mathrm{CO}_{2} \mathrm{Me}$ & $50(\mathrm{R})$ & $70(\mathrm{R})$ \\
\multicolumn{2}{c}{ 2-ciclo-hexen-1-ona } & $36(\mathrm{~S})$ & $74(\mathrm{~S})$ \\
\hline
\end{tabular}

e.e. para a redução da acetofenona). Este resultado foi um dos mais importantes desenvolvimentos em redução assimétrica na época. Corey e colaboradores ${ }^{44}$ descreveram um reagente redutor análogo ainda mais eficiente, a partir da prolina, denominado reagente de Corey-Bakshi-Shibata (CBS) (32) (Figura 8). A alta seletividade observada com o seu uso pode ser devido à discriminação côncavo/ convexo do reagente bicíclico oxazaborolidino, cabendo ressaltar que o estado de transição de seis membros de forma "bote" é também discutido com este reagente ${ }^{44}$.

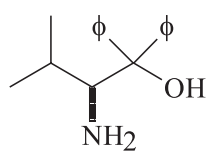

31

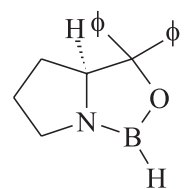

32
Figura 8. Reagentes de Itsuno 31 e de Corey-Bakshi-Shibata (CBS) 32

A maior importância no desenvolvimento do reagente de Corey foi a observação de que a oxazaborolidina isolada atua como um catalisador quiral eficiente nas reações de redução, sendo que apenas uma concentração de 5-10 mol\% de catalisador é necessária para efetuar a redução com alta enantiosseletividade ( $>95 \%$ e.e.). Entre os doadores de hidreto os complexos borano-tetrahidrofurano, borano-dimetilsulfeto (BMS) e catecol-borano são os mais utilizados. Os catalisadores deste tipo podem ser armazenados e manipulados sem complicações e são também mais facilmente preparados ${ }^{45}$, enquanto que os complexos do tipo B-H são sensíveis ao ar e à umidade.

Como exemplo de aplicação, temos a síntese de um intermediário 33 de prostaglandina com diastereosseletividade de 9:1 observada com o catalisador CBS (Esquema 7) ${ }^{22}$. Entretanto, apesar da potencial aplicabilidade deste reagente, poucos exemplos têm sido dados de seu uso em síntese total mesmo recentemente ${ }^{22}$. O mecanismo proposto para a redução via CBS é descrito como envolvendo um estado de transição de 6 membros $^{44}$.

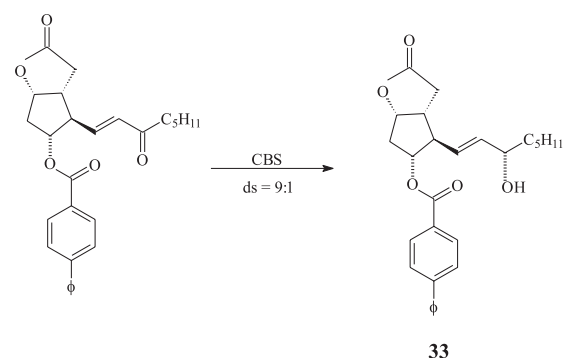

Esquema 7. Síntese de um intermediário da prostaglandina 33 com o uso de $C B S$

Cho e Chun ${ }^{46}$ estabeleceram a síntese de dialquilmonoalcóxiboroidretos quirais 34 (Esquema 8). A síntese envolve a reação de 9BBN com álcoois quirais, seguida pela conversão do éster borônico quiral 35 no boroidreto correspondente. Destes reagentes quirais usando-se um derivado $\alpha$-D-glucose (DIPGF, B) como auxiliar quiral obteve-se um dos mais promissores agentes redutores assimétricos para redução de cetonas. Este reagente é especialmente efetivo para reduções assimétricas de cetonas aromáticas, como nos casos ilustrativos descritos no Esquema 8, e $\alpha$-ceto-ésteres altamente impedidos.

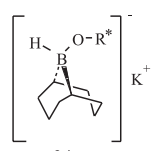

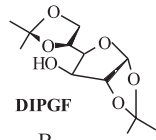

B

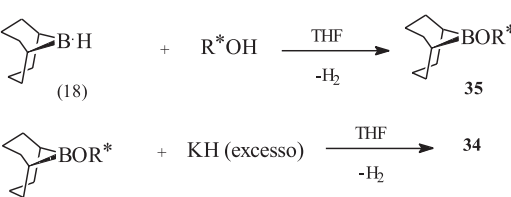<smiles>CC(C)(C)C(=O)c1ccccc1</smiles>

$1 \mathrm{~B}$
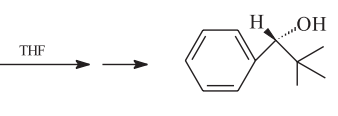

$97 \%$ ee, R<smiles>CC(=O)c1ccccc1C</smiles><smiles>[In]</smiles>

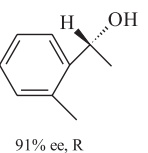

Esquema 8. Obtenção de 37 e redução assimétrica de cetonas aromáticas impedidas

\section{Obtenção de álcoois quirais por uso de métodos catalíticos e eletrocatalíticos}

Os métodos catalíticos para redução assimétrica envolvem o uso de complexos organometálicos ${ }^{19,47}$ com atividade catalítica única, proporcionando a obtenção de métodos de transformação química incomparáveis pela seletividade e eficiência ${ }^{19}$. Para exemplificação, temse o catalisador de Wilkinson - $\mathrm{RhCl}\left(\mathrm{P}_{(}\left(\mathrm{C}_{6} \mathrm{H}_{5}\right)_{3}\right)_{3}$ - que pode ser transformado em catalisador quiral se forem usadas fosfinas oticamente ativas $^{4,48}$. Atualmente, as aplicações da catálise assimétrica em síntese orgânica são muito variadas, abrangendo desde as hidrogenações assimétricas $^{49-51}$ (redução de grupos carbonila ou olefina pró-quirais) até reações de hidroformilação, de ciclopropanação, de Diels-Alder, condensações aldólicas, entre outras ${ }^{49,52-56}$. É importante ressaltar que 
a eficiência destes processos catalíticos assimétricos com complexos quirais, às vezes, é tão alta que é comparável à das enzimas. Os casos de hidrogenação assimétrica são particularmente destacáveis e serão especialmente tratados no caso da hidrogenação assimétrica de cetonas.

O Esquema 9 representa uma reação catalisada de redução assimétrica de um composto carbonílico pró-quiral A, a propiofenona, por um complexo aquiral ou quiral.

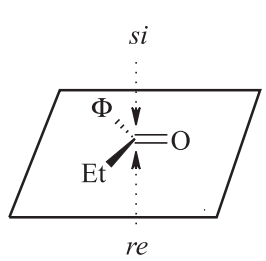

substrato pró-quiral A

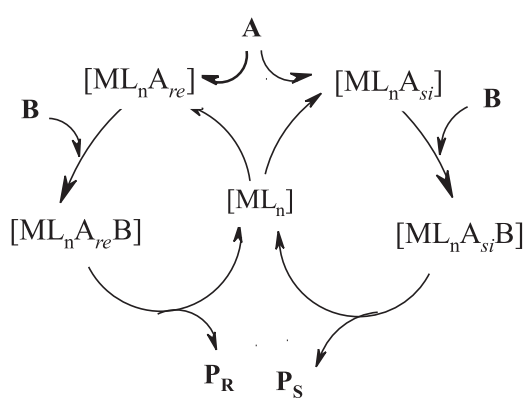

Esquema 9. Representação esquemática de uma reação catalisada por complexo metálico

Um ciclo catalítico, que parte da complexação na face re, leva ao enantiômero (R)-, o outro enantiômero é formado, com a mesma probabilidade, pela complexação na face si em um ciclo catalítico independente ou conectado ao primeiro. Se o catalisador for aquiral, o produto será obtido como uma mistura racêmica. Se o catalisador for quiral, ele irá diminuir a velocidade de formação de um dos enantiômeros, permitindo alta seletividade na formação do outro enantiômero.

\section{Uso de complexos de ródio: catálise química}

O tipo de complexo organometálico mais usual para hidrogenação é o de fosfinas de ródio, particularmente o $\mathrm{RhCl}\left(\mathrm{PPh}_{3}\right)_{3}$, descoberto e estudado por Wilkinson ${ }^{4}$. A hidrogenação de cetonas com complexos fosfina-Rh é lenta mas, ainda assim, através da obtenção de catalisadores quirais pelo uso de fosfinas opticamente ativas disponíveis tornou-se possível a redução quiral de cetonas. Apesar desta redução levar a uma menor estereosseletividade que a redução com substratos olefínicos, estes catalisadores quirais foram sendo aperfeiçoados com o uso de ligantes mais modernos, que serão discutidos a seguir. Na Figura 9 apresentamos os ligantes BPPM $((2 S, 4 S)$ $\mathrm{N}$-(tert-butoxicarbonil)-4-(difenilfosfino)-2-[(difenilfosfino)metil]pirrolidina), CyCAPP ((2S,4S)-N-(tert-butilformami do)-4(dicicloexilfosfino)-2-[(dicicloexilfosfino)-metil]pirrolidina) e BCPM ((2S,4S)-N-(tert-butoxicarbonil)-4-(diciclo-hexilfosfino)-2[(difenilfosfino)metil] pirrolidina) que levam a complexos que apresentam maior seletividade.

A hidrogenação de cetonas com os complexos BPPM, CyCAPP e BCPM resultou em vários métodos de interesse, como a síntese da pantolactona (36) (Figura 10) ${ }^{57}$

Um dos ligantes mais úteis para redução assimétrica de cetonas pró-quirais é o bppfOH 37 (Esquema 10) que é uma ferrocenildifosfina contendo um grupo hidroxila. O complexo catiônico com ródio (I) permite muitas reduções em metanol ( $2 \%$ em água) na faixa de temperatura de $0-30{ }^{\circ} \mathrm{C}$ e sob 50 atm de $\mathrm{H}_{2}$. A acetofenona é reduzida com $40 \%$ e.e. e o ácido pirúvico, $\mathrm{MeCOCO}_{2} \mathrm{H}$, forma o ácido láctico com $83 \%$ e.e. ${ }^{22,58}$. No Esquema 10, o complexo de ródio com bppfOH foi aplicado à síntese da epinefrina 38 , através da redução da amino-cetona com rendimento ótico de $95 \%$.

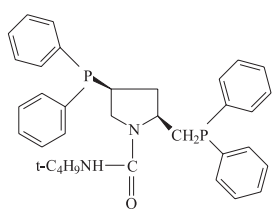

(S,S)-CyCAPP
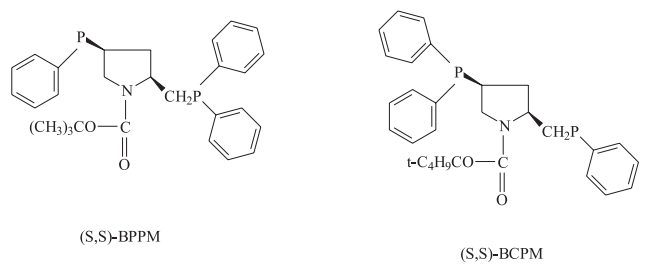

Figura 9. Estruturas de alguns ligantes usados para formação de complexos quirais

\begin{tabular}{ccccc}
\hline $\mathrm{L}^{*}$ & $\mathrm{H}_{2}$, atm & $\begin{array}{c}\% \text { cat, } \\
(\mathrm{mol})\end{array}$ & Configuração & \% e.e. \\
\hline $\begin{array}{c}(2 \mathrm{~S}, 4 \mathrm{~S}) \text {-BPPM } \\
(2 \mathrm{~S}, 4 \mathrm{~S}) \text {-CyCAPP }) \text {-BCPM }\end{array}$ & 50 & 1,1 & $\mathrm{R}$ & 87 \\
\hline & 50 & 0,5 & $\mathrm{~S}$ & 66 \\
\hline
\end{tabular}

Figura 10. Preparação da pantolactona (36) por redução quiral com complexos de $R h(I)$

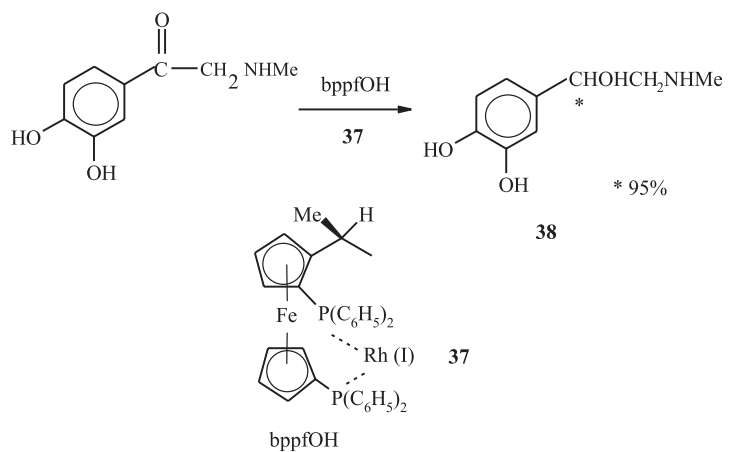

Esquema 10. Obtenção da epinefrina 38 por uso de bppfOH 37

Outros complexos de ródio (I) têm sido muito estudados, como o DIOP ((R,R)-2,3-O-isopropilideno-2,3-diidróxi-1,4-bis(difenilfosfino)butano), BINAP ((R)-2,2'-bis(difenilfosfino)-1,1'-binaftil) e SKEWPHOS ((S,S)-2,4-bis(difenilfosfino)pentano) (Figura 11). Outros complexos de ródio (I) também podem ser citados ${ }^{60-61}$.

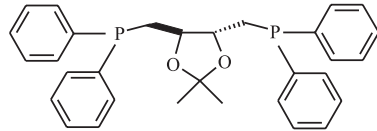

(R,R)-DIOP

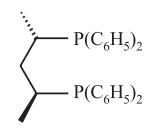

(S,S)-SKEWPHOS

Figura 11. Estruturas dos ligantes DIOP, BINAP e SKEWPHOS 
O catalisador SKEWPHOS-Rh(I) $($ SKEWPHOS $=(\mathrm{S}, \mathrm{S})-2,4-$ bis(difenilfosfino) pentano, ou BDPP) produziu bons resultados ( $82 \%$ de rendimento ótico) na hidrogenação da acetofenona, sendo a reação efetuada por um complexo catiônico ou neutro e na presença de uma amina terciária como catalisador ${ }^{62}$ (Esquema 11).

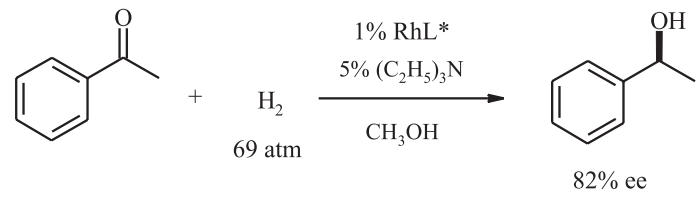

$\mathrm{RhL}^{*}=1 / 2[\mathrm{Rh}(\mathrm{nbd}) \mathrm{Cl}]_{2}+(\mathrm{S}, \mathrm{S})-\mathrm{SKEWPHOS}$

Esquema 11. Uso do catalisador SKEWPHOS-Rh (I) na redução da acetofenona

O mecanismo da hidrogenação catalisada por $\mathrm{Rh}(\mathrm{I})$ envolve a formação de um diidreto de Rh(III), como ilustrado no Esquema 12.

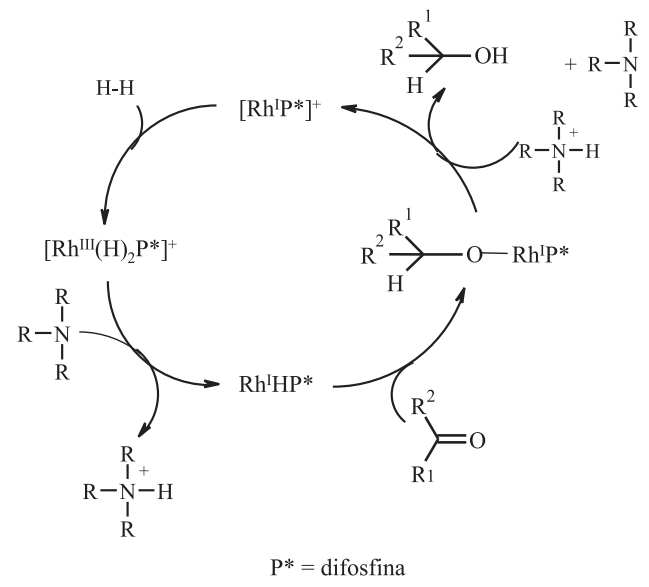

Esquema 12. Mecanismo de hidrogenação catalisada por Rh(I)

Muitos estudos têm sido relatados quanto ao comportamento eletroquímico de complexos de ródio, especialmente bipiridínicos ${ }^{63}$. Há relatos pioneiros sobre o uso de bipiridinas quirais ${ }^{64,65}$, porém, com baixa enantiosseletividade; resultados melhores somente foram obtidos por Bolm e colaboradores ${ }^{66}$, em 1990, que relataram a síntese enantiosseletiva de bipiridinas homoquirais 39 de simetria $\mathrm{C}_{2}$, a análise estrutural por raios- $\mathrm{X}$ de um complexo e as primeiras investigações do uso destas bipiridinas, oticamente ativas, em catálise enantiosseletiva. Em 1992, os autores ${ }^{66}$ descreveram a síntese de outras 2,2'-bipiridinas substituídas de simetria $\mathrm{C}_{2}$ e derivados de piridinas 40 (Figura 12). Bottheghi e colaboradores ${ }^{67}$, no ano anterior, também prepararam um derivado bipiridínico quiral derivado de ácido tartárico 41 com sime-
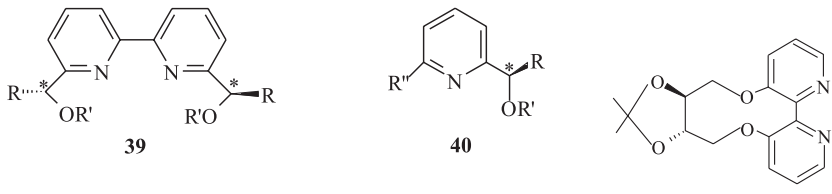

41

Figura 12. 2,2'-bipiridinas 39 e piridinas de simetria $C_{2} 40$ e derivados piridínicos 41 tria $\mathrm{C}_{2}$, porém estes estudos não foram continuados. Cabe ressaltar que, em 1985, Dholakia e colaboradores ${ }^{68}$ relataram que as moléculas de bipiridinas queladas são essencialmente planares, dado importante para a compreensão de muitos resultados de redução assimétrica de cetonas, porém não muito utilizado.

Nishiyama e colaboradores ${ }^{69}$ sintetizaram complexos de tricloreto de bis(oxazolinilpiridina) ródio(III) (42) através da reação de tricloreto de ródio com derivados da bis(oxazolinilpiridina) (pybox), ligantes quirais (Figura 13) preparados a partir do ácido piridinil-2,6dicarboxílico e derivados da valina e da leucina.

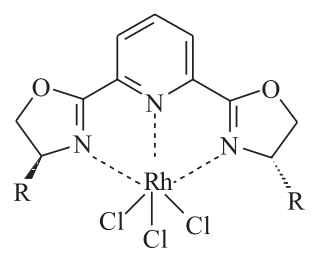

42

$$
\mathrm{R}=\mathrm{i}-\mathrm{Pr}, \mathrm{s}-\mathrm{Bu} \text { ou } \mathrm{t}-\mathrm{Bu}
$$

Figura 13. Complexos de tricloreto de bis(oxazolinilpiridina)ródio(III) (42)

Em 1991, Nishiyama et al. ${ }^{70}$ descreveram que o complexo (S,S)ip-pybox-ródio, com a ajuda de $\mathrm{AgBF}_{4}$, mostrou um nível extremamente alto de enantiosseletividade para a redução de derivados da acetofenona, acima de $90 \%$ de e.e. em média. Sob as mesmas condições, obteve-se uma completa seleção da face pró-quiral de 1-tetralona com $99 \%$ e.e.. Os autores examinaram cetonas $\alpha, \beta$-insaturadas, resultando numa exclusiva redução 1,2 para benzalacetona, $\beta$-ionona e chalcona, porém com baixa enantiosseletividade. Com relação ao efeito de substituintes nos anéis oxazolínicos, observaram que as velocidades de redução são fortemente afetadas pelo volume dos substituintes nos anéis.

Ainda, Nishiyama et al.$^{71-73}$ estudaram outros redutores oxazolidínicos quirais e observaram principalmente a estereosseletividade na redução de cicloexanonas, substituídas com o catalisador quiral ródio/bis(oxazolinil)piridina e difenilsilano. Como exemplo, 4-tert-butil-ciclo-hexanona gera o álcool trans(equatorial) predominantemente, com a razão dos álcoois trans/cis, 67:33. A 2-metilciclo-hexanona foi reduzida a uma mistura de trans- e cis-2metilcicloexanóis com 88\% de rendimento; a razão dos álcoois trans/ $c i s=41: 59$. Cada álcool mostrou uma alta pureza enantiomérica, indicando que a seleção da face $r e / s i$, pelo catalisador, predomina sobre o ataque axial/equatorial (seleção trans/cis).

Brunner e Brandl ${ }^{74}$ investigaram o comportamento de piridinoxazolina 43 e seu análogo 6-metil-picolinoxazolínico 44 (Figura 14), como co-catalisadores na hidrosililação enantiosseletiva da acetofenona catalisada por ródio. Eles observaram que a indução ótica é invertida da piridinoxazolina para a picolinoxazolina, sendo que um excesso de 1:2 deste ligante é necessário para se obter os maiores excessos enantioméricos, cerca de $48 \%$.<smiles>CCC1COC(c2ccccn2)=N1</smiles>

43<smiles>CCCCCCCCCCCCCCCCCC</smiles>

44
Figura 14. Ligantes piridinoxazolina 43 e picolinoxazolina 44 
A hidrosililação enantiosseletiva da acetofenona e difenilsilano com $[\mathrm{Rh}(\mathrm{Cod}) \mathrm{Cl}]_{2}$ e os co-catalisadores piridinoxazolidínicos também foi investigada ${ }^{75-76}$. Esses autores observaram ${ }^{75}$ que a substituição do hidrogênio na posição 6 do anel piridínico reduz a dependência da indução ótica com o excesso de ligante, solvente, e concentração de difenilsilano, acetofenona e catalisador. Considerou-se que os substituintes bloqueiam um dos sítios de coordenação do ródio, impedindo interações adicionais com ligantes, solventes, substratos e aditivos; além do mais, observou-se que derivados fenantrolínicos e bipiridínicos apresentaram excelente e.e. ${ }^{76}$.

Kuwano e colaboradores ${ }^{77}$ relataram a destacável hidrosililação assimétrica de várias dicetonas simétricas catalisada por complexos EtTRAP-ródio $($ TRAP $=(\mathrm{S}, \mathrm{S})-2,2$ "-bis[(R)-1-(dialquilfosfino $)$ etil]1,1"-bis-ferroceno), obtendo-se os dióis simétricos oticamente ativos correspondentes, excelentes "chirons" ("synthons" quirais) com altos excessos enantioméricos (Esquema 13).

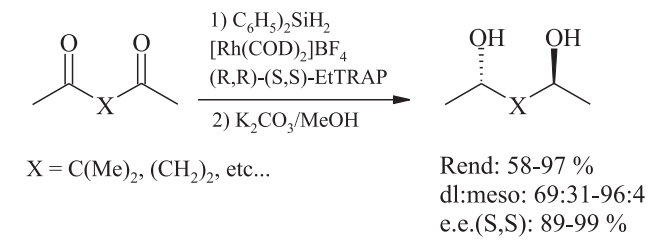

(R,R)-(S,S)-EtTRAP: (R,R)-(S,S)-(MePEt $\left.t_{2} \mathrm{CH}\right) \mathrm{FeCp}-\mathrm{FeCp}\left(\mathrm{CHMePEt}_{2}\right)$

Esquema 13. Obtenção de dióis quirais por uso de Er-TRAP-ródio

\section{Uso de complexos de rutênio: catálise química}

Os complexos de rutênio são também muito estudados em redução assimétrica. Especificamente, obtem-se os melhores resultados na hidrogenação assimétrica de olefinas pelo uso de complexo diacetato de $\mathrm{Ru}(\mathrm{II})-\mathrm{BINAP}^{19}$. Os complexos de rutênio, na forma de $\mathrm{Ru}(\mathrm{II})$, contendo halogênio e com a fórmula empírica $\mathrm{RuX}_{2}$ (BINAP), onde $\mathrm{X}=\mathrm{Cl}$, Br ou I ou $\left[\mathrm{RuCl}_{2}(\mathrm{BINAP})\right]_{2} \mathrm{~N}\left(\mathrm{C}_{2} \mathrm{H}_{5}\right)_{3}$, são excelentes catalisadores, assim como os complexos catiônicos do tipo $[\mathrm{RuX}$ (binap)(areno) $] \mathrm{Y}$, onde $\mathrm{X}=$ halogênio e $\mathrm{Y}=$ halogênio ou $\mathrm{BF}_{4}{ }^{78}$.

O esquema geral da indução assimétrica (Esquema 14a) ilustra a maior aplicabilidade dos complexos $\mathrm{RuX}_{2}$ (BINAP), a redução de derivados $\alpha$-, $\gamma$ - e especialmente $\beta$-carbonílicos substituídos; sugere-se que os intermediários-chave devem ser complexos quelados de 5 a 7 membros, nos quais o átomo de Ru(II) interage com o oxigênio da carbonila e com um heteroátomo $\mathrm{X}^{79}$. Este esquema geral mostra também o amplo escopo da utilização deste tipo de complexo Ru(II)BINAP onde se podem obter os dois enantiômeros possíveis de $\alpha$-, $\beta$ - e $\gamma$-hidróxi-derivados substituídos diversos e com importantes aplicações sintéticas ${ }^{19}$ (Esquema 14b). É digno de nota que o Ru(II)BINAP é sem dúvida o reagente de melhores resultados, com e.e. até

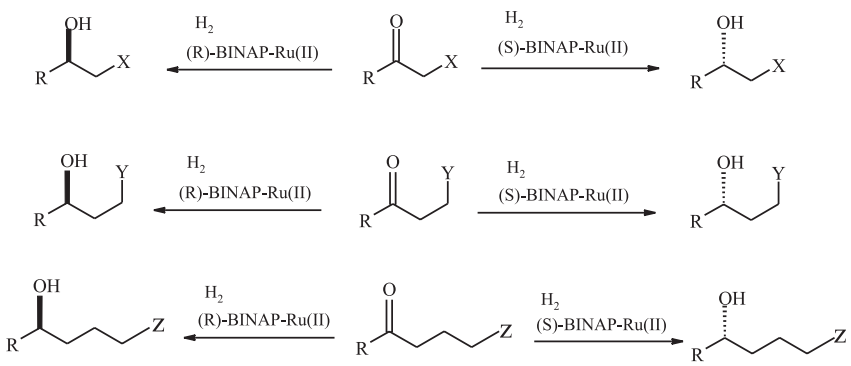

Esquema 14a. Esquema geral da hidrogenação enantiosseletiva

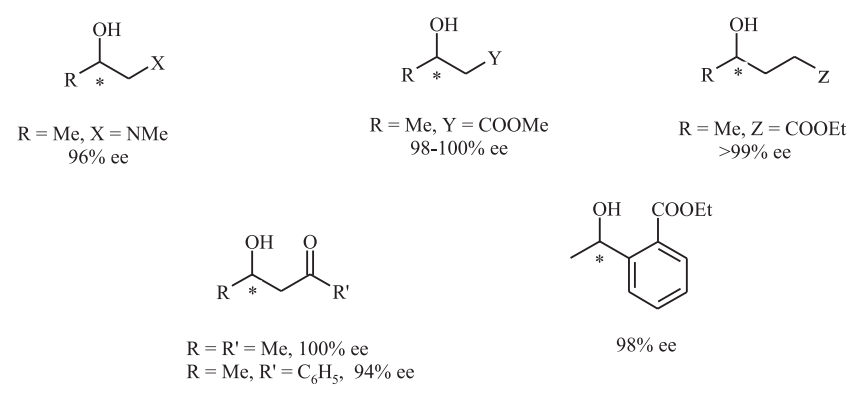

Esquema 14b. Dados de e.e. da redução catalítica de cetonas substituídas

maiores que $99 \%$, para a obtenção do insumo quiral 3-hidróxibutanoato de etila (1) (Figura 1) e derivados por redução da cetona pró-quiral correspondente ${ }^{19,79}$. Particularmente, vale destacar que apesar da possível obtenção dos quatro enantiômeros de 1,3-dióis, por dupla redução enantiosseletiva, o Ru(II)-BINAP só leva satisfatoriamente ao $(\mathrm{R}, \mathrm{R})^{19,79}$.

As aplicações sintéticas da redução assimétrica de Ru(II)-BINAP para a preparação de produtos naturais ou sintéticos de interesse são diversos mas, destacamos o seu uso como redutor de derivados $\beta$ ceto-substituídos na etapa-chave para obtenção de álcool intermediário quiral (Figura 15) para diversas sínteses, tais como síntese da compactina e mevinolina $(45 \mathbf{a} \text { e } \mathbf{b})^{80}$, potentes inibidores da biossíntese do colesterol; de FK506 (46) ${ }^{81}$, potente inibidor de genes de ativação de células-T; da gloesporona $(47)^{82}$, potente inibidor de germinação de esporos e da (-)-indolizidina $223 \mathrm{AB}(\mathbf{4 8})^{83}$, com várias aplicações biológicas de interesse.

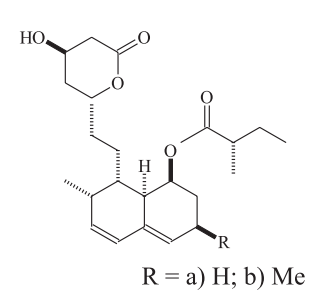

45

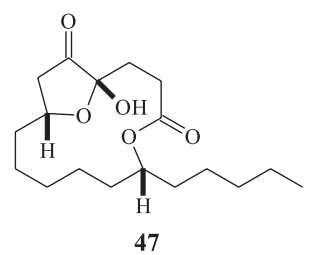

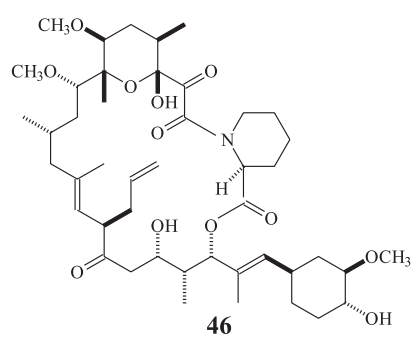

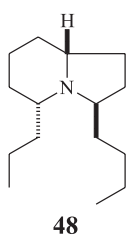

Figura 15. Substâncias preparadas via redução assimétrica de $\beta$ carbonilados com Ru(II)-BINAP

\section{Uso de complexos de ródio e de rutênio: eletrocatálise}

A síntese eletroquímica assimétrica é ainda incipiente quando comparada aos métodos enzimáticos, catalíticos e químicos ${ }^{84}$. O princípio da catálise de reações eletroquímicas (eletrocatálise) é a aceleração da transferência eletrônica entre o eletrodo e o substrato, pela utilização de catalisador apropriado que atua como transportador de elétrons entre o substrato e o eletrodo, Esquema 15. Pode-se, então, ter a eletrocatálise homogênea, onde o fenômeno da transferência de elétrons ocorre entre o mediador no seio da solução, ou ainda a eletrocatálise heterogênea, através da formação de eletrodos modificados, no qual a imobilização de complexos metálicos desperta grande 
interesse. O termo eletrodo modificado (EM) refere-se a todo eletrodo em cuja superfície um reagente é fixado. Estas modificações na superfície melhoram a eficácia e a seletividade das reações, uma vez que o eletrodo adquire as propriedades das espécies fixadas em sua superfície, propriedades eletroquímicas, químicas e óticas. São numerosas as vantagens de utilizar-se EM, entre elas:

- uso de quantidades extremamente pequenas de mediador/ catalisador (reagente redox);

- $\quad$ sensibilidade em relação às condições de reação;

- possível aplicação a reações catódicas e anódicas, com expectativa de que as sequiências de reação sejam similares às da fase homogênea, sem necessidade de recuperá-los por isolamento;

- maior possibilidade de indução assimétrica, com polímeros capazes de arquitetar um ambiente quiral e de servir como hospedeiros para enzimas redox.

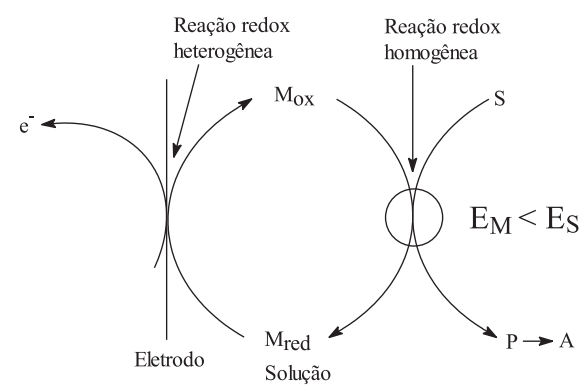

Esquema 15. Transferência eletrônica indireta entre um eletrodo e um substrato $S$ por intermédio de um mediador $M$ (exemplo de uma oxidação)

As aplicações de complexos de ródio em eletrocatálise têm sido muito investigadas por Moutet e colaboradores e, apesar da maior parte das investigações não se referir à eletrocatálise assimétrica enantiosseletiva, têm-se excelentes resultados de diastereosseletividade. Oliveira e Moutet ${ }^{85,86}$ relataram a hidrogenação eficiente da carvona e de algumas cicloexanonas substituídas sobre eletrodos de carbono modificados por filmes poliméricos, obtidos pela eletropolimerização oxidativa do complexo $\left[\mathrm{Rh}^{\mathrm{III}}\left(\mathrm{L}_{1}\right)_{2}(\mathrm{Cl})_{2}\right]\left[\mathrm{BF}_{4}\right]$ onde têm-se ligantes bipirídinicos pirrol-substituídos para a eletropolimerização através do anel pirrólico e a formação de um eletrodo modificado recoberto pelo filme formado. Uma diferença marcante de seletividade foi encontrada na hidrogenação de substratos volumosos sobre o cátodo catalítico, quando se compara sua hidrogenação catalítica ou eletrocatalítica com complexos similares usados em meio homogêneo. Além disso, o sistema catalítico mostrou ser mais eficiente que o homogêneo. A caracterização eletroquímica, em eletrólitos orgânicos, de uma série de complexos do tipo $\left[\mathrm{Rh}^{\mathrm{III}}(\mathrm{L})_{2} \mathrm{Cl}_{2}\right]^{+}$contendo derivados de 2,2'-bipiridina como ligantes foi efetuada pelos mesmos autores ${ }^{86}$. De acordo com eles, a re-oxidação de sua forma duplamente reduzida, $\left[\mathrm{Rh}^{\mathrm{I}}(\mathrm{L})_{2}\right]^{+}$, leva tanto ao material de partida quanto à $\left[\mathrm{Rh}^{\mathrm{III}}(\mathrm{L})_{2}(\mathrm{~S})_{2}\right]^{3+}$, de acordo com as propriedades de coordenação do solvente.

Em relação ao uso de complexos de ródio na formação de eletrodos modificados, e aplicações em redução eletrocatalítica de cetonas, cabe mencionar os estudos de Moutet e colaboradores ${ }^{87-89}$.

A hidrogenação eletrocatalítica (HEC) de cicloexanona a cicloexanol pode ser conseguida empregando-se um EM, C/poli$\left[\mathrm{Rh}^{\mathrm{III}}\left(\mathrm{L}_{8}\right)_{2} \mathrm{Cl}_{2}\right]^{+}$, a um potencial em que um intermediário cataliticamente ativo, $\mathrm{Rh}(\mathrm{I})$, é formado ${ }^{90}$. Investigações posteriores mostraram que o eletrodo catalítico pode hidrogenar eficientemente cicloexanonas substituídas e carvona. A HEC de 2- e 3-metilciclo- exanona conduz a 95\% de cis-2-metilcicloexanol, de forma similar ao procedimento usado na hidrogenação catalítica com $\left[\mathrm{Rh} \text { (bipy) } \mathrm{Cl}_{2}\right]^{+}$. Diferenças marcantes foram observadas na regio- e estereosseletividade comparando-se o sistema eletrocatalítico no eletrodo modificado com o sistema em meio homogêneo. Na HEC da 4-terc-butilcicloexanona, o produto formado apresenta uma estereosseletividade reversa (73\% do álcool trans-terc-butilcicloexanol é obtido) quando comparada com a hidrogenação catalítica em meio homogêneo (77\% do mesmo álcool cis- obtido). Esta estereosseletividade reversa pode ser devido à modificação do meio em que se encontra o centro catalítico no complexo polimerizado.

Estudos mais recentes, com eletrodos de carbono modificados por eletropolimerização de complexos bipiridínicos substituídos, análogos aos do tipo $\left[\mathrm{Ru}^{\mathrm{III}}(\mathrm{L})_{2} \mathrm{Cl}_{2}\right]^{+}\left(\mathrm{L}=\mathrm{L}_{2}, \mathrm{~L}_{3} \text {, etc... }\right)^{91}$, mostraram que o uso de uma cadeia alquílica ligando os complexos ao esqueleto polipirrólico, ao invés de um carbóxi-éster, aumenta a estabilidade destes eletrodos provavelmente pela hidrólise da ligação éster ${ }^{91}$.

Apesar destes resultados promissores de regio- e estereosseletividade no uso de complexos de ródio e de rutênio não-quirais na eletrocatálise redutiva de cetonas, o emprego de eletroquímica na redução assimétrica de cetonas é raro. Os métodos apresentados envolvem a aplicação de eletrólitos quirais ${ }^{92}$, ou solventes quirais ${ }^{93}$, ou com a superfície de cátodos de mercúrio modificada pela absorção de alcalóides como auxiliares quirais ${ }^{94}$. A redução de compostos carbonílicos pró-quirais teve o seu estudo pioneiro efetuado por Miller et $a l .{ }^{95}$ que estudaram eletrodo de grafite derivatizado com aminoácidos. Posteriormente Fujihira et al..$^{96}$ investigaram o uso de eletrodos de níquel de Raney modificados por ácido tartárico opticamente ativo.

$\mathrm{O}$ uso de eletrodos modificados para eletrocatálise assimétrica (eletrocatálise heterogênea) em redução de cetonas ainda é mais restrito. Na literatura, apenas Moutet et al..$^{97}$ (Figura 16a) investigaram o uso de hidrogenação eletrocatalítica assimétrica heterogênea com complexos de ródio dos ligantes $49 \mathbf{a}-49 \mathbf{c}$, pelo uso de complexos de ródio (III) com ligantes polipiridínicos quirais 49d (Figura 16a) e com derivados fenantrolínicos 50 (Figura 16b). Os melhores resultados obtidos (e.e.) na redução da acetofenona (ca. 15\%) foram ob-

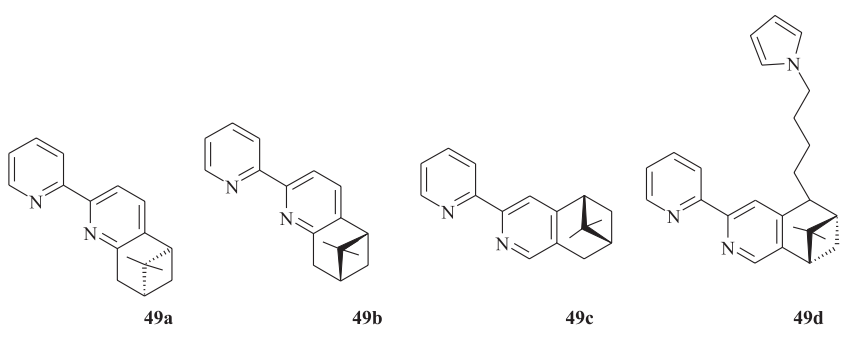

Figura 16a. Ligantes bipiridínicos quirais usados em eletrocatálise assimétrica para redução da acetofenona
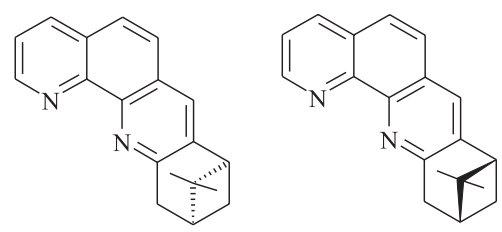

$50 a$

$\mathbf{5 0 b}$

Figura 16b. Ligantes bipiridínicos quirais usados em eletrocatálise assimétrica para redução da acetofenona 
tidos com o derivado 49c, estes resultados não são tão bons (7 a 14\% de e.e) quanto os obtidos por catálise química, mas são promissores, confirmando a aplicabilidade potencial do uso da técnica de eletrossíntese assimétrica quer em fase homogênea, quer em fase heterogênea (eletrodos quirais). Além do mais, o catalisador quiral pode ser facilmente recuperado e reutilizado e a extração do produto reduzido quiral obtido é também facilitada.

\section{CONCLUSÕES}

Os álcoois quirais são importantes insumos industriais, além de substratos para a construção de importantes classes estruturais de produtos naturais ou de moléculas de interesse biológico. A obtenção de álcoois quirais por redução assimétrica de cetonas pró-quirais por redutores quirais, é, de fato, uma importante área de pesquisa e de desenvolvimento dentro da síntese assimétrica. Dentre suas aplicações destacam-se:

- os métodos químicos com uso de organoaluminatos, particularmente o BINAL-H, e suas aplicações em síntese total, obtendose na maioria das vezes altos índices de e.e. e ainda podendo-se obter os dois álcoois enantioméricos possíveis;

os métodos químicos com o uso de organoboranos, também com diversas aplicações em síntese total. Vários destes reagentes de boro são de grande eficiência e até comercializados como o alpino-borano (R)-e (S)- Aldrich $^{\oplus}$ : Alpine-Borane) e o $B$ clorodiisopinocanfeilborano (ou $\mathrm{Ipc}_{2} \mathrm{BCl}$ ) (Aldrich ${ }^{\circledR}$ : DIPchloride ${ }^{\circledR}$ ). Contudo, o organoborano mais eficiente, em rendimento, em obtenção de altos excessos enantioméricos e de ampla aplicação é o o Eap 2 BCl (B-clorodiiso-2-etil-aponinocanfeilborano);

os métodos catalíticos com o uso de complexos de ródio (I), onde há uma grande variedade de ligantes estudados. Ainda assim, o fator limitante é o alto custo do ródio;

- o uso de complexos de rutênio (II), especialmente o Ru(II)BINAP, para a obtenção de álcoois funcionalizados. Como exemplo, os álcoois quirais $\beta$-carbalcóxi-substituídos e outros com excelentes rendimentos e altos excessos enantioméricos. Particularmente, a preparação de $\alpha, \gamma$-dióis com os dois carbonos hidroxilados de configuração absoluta determinada $(\mathrm{R}, \mathrm{R})$ - é digna de nota; entretanto o uso de EtTRAP-ródio leva ao enantiômero $(\mathrm{S}, \mathrm{S})$-;

- os complexos quirais de rutênio (II) acima citados em muitas aplicações de síntese total em etapa-chave como agente redutor assimétrico de compostos carbonílicos;

- os métodos eletrocatalíticos que, apesar de ainda serem pouco estudados para a redução assimétrica, mostram-se como potencial área de investigação.

\section{AGRADECIMENTOS}

Ao CNPq, à FAPEMIG e à FUNDEP-UFMG pelo apoio financeiro e pelas bolsas concedidas.

\section{REFERÊNCIAS}

1. Eliel, E.L.; Wilen, S.H.; Mander, L.N.; Stereochemistry of Organic Compounds, John Wiley \& Sons Inc.: New York, 1994, cap.12.

2. Marckwald, W.; Ber. Deutsch. Chem. Ges. 1904, 37, 349 e 1369; Jacques, J.; Bull. Soc. Chim. Fr. 1995, 132, 353.

3. Pinheiro, S.; Ferreira, V.F.; Quim. Nova 1998, 21, 312.

4. Kagan, H.B. Em Comprehensive Organometallic Chemistry; Wilkinson, G; Stone, G. A., eds.; Pergamon Press: London, 1982, vol. 8, cap. 53.

5. Seebach, D.; Zuger, M.; Helv. Chim. Acta 1982, 65, 495; Sugai, T.; Katoh, O.; Ohta, H.; Tetrahedron 1995, 51, 11987; Mori, K.; Chem. Commun. 1997, 1153.
6. Fráter, G.; Helv. Chim. Acta 1979, 62, 2825; ibid, 1979, 62, 2829

7. MacLeod, R.; Prosser, H.; Fikentscher, L.; Lanyi, J.; Mosher, H.S.; Biochemistry 1964, 3, 838; Vesonder, R. F.; Stodola, F. H.; Wickerham, L. J.; Ellis, J. J.; Rohwedder, W. K.; Can. J. Chem. 1971, 49, 2829.

8. Prelog, V.; Pure Appl. Chem. 1964, 9, 119; Bestmann, H.-J.; Schobert, R.; Tetrahedron Lett. 1987, 28, 6587.

9. Züger, M.F.; Weller, T.; Seebach, D.; Helv. Chim. Acta 1980, 63, 2005.

10. Kramer, A.; Pfander, H.; Helv. Chim. Acta 1982, 65, 293.

11. Ho, Tse-Lok; Enantioselective Synthesis - Natural Products From Chiral Terpenes, John Wiley \& Sons, Inc.: New York, 1992.

12. Barrett, A.G.M.; Carr, R.A.E.; Attwood, S.V.; Richardson, G.; Walshe, N.D.A.; J. Org. Chem. 1986, 51, 4840.

13. Tapolczay, D.J.; Thomas, E.J.; Whitehead, J.W.F; Chem. Commun. 1985 , 143 .

14. Emberger, R.; Hopp, R.; Spec. Chem. 1987, 7, 193.

15. Nógrádi, M.; Stereoselective Synthesis, $2^{\text {nd }}$ ed., VCH Publishers; Weinheim: New York, 1995; Morrison, J.D.; Mosher, H.S.; Asymmetric Organic Reactions, $2^{\text {nd }}$ ed., American Chemical Society: Washington, 1976.

16. Mori, K.; Tetrahedron 1989, 11, 3233.

17. Takken, W.; Invertebr. Reprod. Dev. 1999, 36, 67

18. Silva, D. F.; Eiras, A. E.; Vasconcelos, S. D.; International Congress of Entomology, Book-XXI, I, 2000.

19. Noyori, R.; Asymmetric Synthesis of Natural Products, John Wiley \& Sons, Inc.: New York, 1994; Singh, V. K.; Synthesis 1992, 605; Noyori, R.; Asymmetric Catalysis in Organic Synthesis, John Wiley \& Sons, Inc.: New York, 1994.

20. Tomioka, K.; Synthesis 1990, 541.

21. Noyori, R.; Tomino, I.; Tanimoto, Y.; Nishizawa, M.; J. Am. Chem. Soc. 1984, 106, 6709

22. Koshinen, A.; Asymmetric Synthesis of Natural Products, John Wiley \& Sons, Londres, 1984; Kanoh, N.; Ishihara, J.; Yamamoto, Y.; Murai A.; Synthesis 2000, 1878.

23. Suzuki, M.; Morita, Y.; Koyano, H.; Koga, M.; Noyori, R.; Tetrahedron 1990, 46, 4809.

24. Babudri, F.; Fiandanese, V.; Marchese, G.; Punzi, A.; Tetrahedron 2000, $56,327$.

25. Brown, H.C.; Ramachandran, P.V. Em Advances In Asymetric Synthesis; Hassner, A., ed.; JAI Press: London, 1995, vol. 1, p. 147.

26. Brown, H.C.; Ramachandran, P.V.; J. Organomet. Chem. 1995, 500, 1.

27. Brown, H.C.; Mandal, A. K; J. Org. Chem. 1977, 42, 2996; ibid, 1984, 49, 2558.

28. Midland, M.M.; Greer, S.; Tramontano, A.; Zderic, S. A.; J. Am. Chem. Soc. 1979, 101, 2352.

29. Midland, M. M.; Tramontano, A.; Kazubski, A.; Graham, R. S.; Tsai, D. J. S.; Cardin, D.B.; Tetrahedron 1984, 40, 1371.

30. Midland, M.M.; McLoughlin, A.; J. Org. Chem. 1984, 49, 1317.

31. Rogic, M.M.; J. Org. Chem. 1996, 61, 1341.

32. Midland, M.M.; Tramontano, A.; Tetrahedron Lett. 1980, 21, 3549.

33. Midland, M.M.; Nguyen, N.H.; J. Org. Chem. 1981, 46, 4107.

34. Johnson, W.S.; Frei, B.; Gopalan, A. S.; J. Org. Chem. 1981, 46, 1512.

35. Brown, H.C.; Chandrasekharan, J.; Ramachandran, P.V.; J. Am. Chem. Soc. 1988, 111, 1539; Brown, H.C.; Chandrasekharan, J.; Ramachandran, P.V.; Heteroat. Chem. 1995, 6, 1.

36. Srebnik, M.; Ramachandran, P.V.; Brown, H.C.; J. Org. Chem. 1988, 53, 2916.

37. Brown, H.C.; Chandrasekharan, J.; Ramachandran, P.V.; J. Org. Chem. 1986, $51,3394$.

38. Brown, H.C.; Ramachandran, J.; Weissman, S.A.; Swaminathan, S.; J. Org. Chem. 1990, 55, 6328.

39. Brown, H.C.; Ramachandran, J; Swaminathan, S.; Tetrahedron: Asymmetry 1990, 1,433 .

40. Brown, H.C.; Ramachandran, J; Teodrovic, A.V.; Swaminathan, S.; Tetrahedron Lett. 1991, 32, 6691.

41. Brown, H.C.; Ramachandran, J.; Park, W.S.; Cho, B.T.; J. Org. Chem. 1987, $52,5406$.

42. Itsuno, S.; Ito, K.; Hirao, A.; Nakahama, S.; J. Chem. Soc., Chem. Commun. 1983, 469.

43. Itsuno, S.; Ito, K.; Sakurai, Y.; Hirao, A.; Nakahama, S.; Bull. Chem. Soc. Jpn. 1987, 60, 395

44. Corey, E.J.; Bakshi, R.K.; Shibata, S.; J. Am. Chem. Soc. 1987, 109, 5551.

45. Corey, E.J.; Bakshi, R.K.; Shibata, S.; Chen, C. P.; Sing, V.K.; J. Am. Chem. Soc. 1987, 109, 7925.

46. Cho, B.T.; Chun, Y.S.; Tetrahedron: Asymmetry 1992, 3, 73.

47. Seebach, D.; Angew. Chem., Int. Ed. 1988, 27, 1624.

48. Zassinovich, G.; Mestroni, G.; Gladiali, S.; Chem. Rev. 1992, 92, 1051

49. Noyori, R.; Science 1990, 248, 1194

50. Noyori, R.; Chem. Soc. Rev. 1989, 18, 187. 
51. Noyori, R.; Takaya, H.; Acc. Chem. Res. 1990, 23, 345.

52. Noyori, R.; Chemtech 1992, 22, 360.

53. Brunner, H.; Synthesis 1989, 645.

54. Brown, J. M.; Davies, S. G.; Nature 1989, 342, 631.

55. Ojima, I.; Clos, N.; Bastos, C.; Tetrahedron 1989, 45, 6901.

56. Blystone, S.L.: Chem. Rev. 1989, 89, 1663

57. Morimoto, T.; Takahashi, H.; Achiwa K.; Chem. Pharm. Bull. 1994, 42, 481.

58. Hayashi, T.; Mise, T.; Mitachi, S.; Yamamoto, K; Kumada, M.; Tetrahedron Lett. 1976, 1133.

59. Hayashi, T.; Katsumura, A.; Konishi, M.; Kumada, M.; Tetrahedron Lett. 1979, 425 .

60. Tani, K.; Tanigawa, E.; Tatsuno, Y.; Otsuka, S.; Chem. Lett. 1986, 737.

61. Wang, H.; Sakata, T.; Azuma, M.; Ohta, T.; Takaya, H.; Chem. Lett. 1990, 1331.

62. Bakos, J.; Toth, I.; Heil, B.; Marko, L.; J. Organomet. Chem. 1985, 279, 23.

63. Kew, G.; Dearmond, K.; Hanck, K.; J. Phys. Chem. 1974, 78, 727.

64. Botteghi, C.; Caccia, C.; Chelucci, G.; Soccolini, F.; J. Org. Chem. 1984, 49, 4290 .

65. Botteghi, C.; Chelucci, G.; Chessa, G.; Delogu, G.; Gladiali, S.; Soccolini, F.; J. Organomet. Chem. 1986, 304, 217.

66. Bolm, C.; Zehnder, M.; Bur, D.; Angew. Chem., Int. Ed. 1990, 29, 205; Bolm, C.; Ewald, M.; Felder, M.; Schlingloff, G.; Chem. Ber. 1992, 125, 1169 .

67. Botteghi, C.; Schionato, A.; Delucchi, O.; Synth. Commun. 1991, 21, 1819.

68. Dholakia, S.; Gillard, R.D.; Wimmer, F.L.; Polyhedron 1985, 4, 791.

69. Nishiyama, H.; Sakaguchi, H.; Nakamura, T.; Horihata, M.; Kondo, M.; Itoh, K.; Organometallics 1989, 8, 846.

70. Nishiyama, H.; Kondo, M.; Nakamura, T.; Itoh, K.; Organometallics 1991, 10,500 .

71. Nishiyama, H.; Yamaguchi, S.; Kondo, M.; Itoh, K.; J. Org. Chem. 1992, $57,4306$.

72. Nishiyama, H.; Park, S.B.; Itoh, K.; Tetrahedron: Asymmetry 1992, 3, 1029.

73. Nishiyama, H.; Yamaguchi, S.; Park, S. B.; Itoh, K.; Tetrahedron: Asymmetry. 1993, 4, 143.

74. Brunner,H.; Brandl, P.; J. Organomet. Chem. 1990, 390, C81.

75. Brunner,H.; Brandl, P.; Tetrahedron: Asymmetry 1991, 2, 919.

76. Gladiali, S.; Pinna, L.; Delogu, G.; Graf, E.; Brunner, H.; Tetrahedron: Asymmetry 1990, 1, 931 .

77. Kuwano, R.; Sawamura, M.; Shirai, J.; Takahashi, M.; Ito, Y.; Tetrahedron Lett. 1995, 36, 5239.
78. Mashima, K.; Kusano, K.; Ohta, T.; Noyori, R.; Takaya, H.; J. Chem. Soc. Chem. Commun. 1989, 1208.

79. Kitamura, M.; Ohkuma, T.; Inoue, S.; Sayo, N.; Kumobayashi, H.; Akutagawa, S.; Ohta, T.; Takaya, H.; Noyori, R.; J. Am. Chem. Soc. 1988, 110, 629; Noyori, R.; Ohkuma, T.; Kitamura, M.; Takaya, H.; Sayo, N.; Kumobayashi, H.; Akutagawa, S.; J. Am. Chem. Soc. 1987, 109, 5856; Kawano, K.; Ishii, Y.; Saburi, M.; Uchida, Y.; J. Chem. Soc. Chem. Commun. 1988, 87; Shao, L.; Kawano, H.; Saburi, S.; Uchida, Y.; Tetrahedron 1993, 49, 1997.

80. Shao, L.M.; Seki, T.; Kawano, H.; Saburi, M.; Tetrahedron Lett. 1991, 32, 7699.

81. Jones, A. B.; Yamaguchi, M.; Patten, A.; Danishefski, J.; Ragan, J. A.; Smith, D. B.; Schreiber, S. L.; J. Org. Chem. 1989, 54, 17; Nakatsuka, M.; Ragan, J. A.; Sammakia, T.; Smith, D. B.; Uehling, D. E.; Schreiber, S. L.; J. Am. Chem. Soc. 1990, 112, 5583.

82. Schreiber, S. L.; Kelly, S.E.; Porco, J. A.; Sammakia, T.; Suh, E. M.; J. Am. Chem. Soc. 1988, 110, 6210.

83. Taber, D.F.; Deker, P.B.; Silverberg, L.J.; J. Org. Chem. 1992, 57, 5990.

84. Tallec, A.; Bull. Soc. Chim. Fr. 1984, 743

85. Oliveira, I. M. F.; Moutet, J.-C.; J. Mol. Catal. 1993, 81, L19.

86. Oliveira, I. M. F.; Moutet, J.-C.; J. Electroanal. Chem. 1993, 361, 203.

87. Bettega, H. C. -Y.; Moutet, J.-C.; J. Electroanal. Chem. 1994, 364, 271.

88. Chardon-Noblat, S.; Oliveira, I. M. F.; Moutet, J.-C., Tingry, S.; J. Mol. Catal. A: Chem. 1995, 13

89. Bettega, H.C.; Moutet, J.-C., J. Electroanal. Chem. 1994, 364, 271.

90. Oliveira, I. M. F.; Moutet, J.-C.; Vlachopoulos, N.; J. Electroanal. Chem. 1990, 291, 243

91. Schnyder, A.; Togni, A.; Wiesli, U.; Organometallics 1997, 16, 255.

92. Kariv, E.; Terni, H. A.; Gileadi, E.; J. Electrochem. Soc. 1990, 120, 639; Horner, L. Em Organic Electrochemistry; Lund, H.; Baizer, M. M., eds.; Marcel Dekker: New York, $2^{a}$ ed., 1983, p. 945.

93. Seebach, D.; An Oei, H.; Angew. Chim., Int. Ed. 1975, 14, 634.

94. Gourley, R. N.; Grimshaw, J.; Millard, P. G.; J. Chem. Soc. C 1970, 2318; Kopilov, J.; Kariv, E.; Miller, L. L.; J. Am. Chem. Soc. 1977, 99, 3450; Hazard, R.; Jaouannet, S.; Tallec, A.; Tetrahedron 1982, 38, 93.

95. Watkins, B. F.; Behling, J. R.; Kariv, E.; Miller, L. L.; J. Am. Chem. Soc. $\mathbf{1 9 7 5}, 97,3549$

96. Fujihira, M.; Yokosawa, A.; Kinoshita, H.; Osa, T.; Chem. Lett. 1982, 1089.

97. Moutet, J.-C.; Cho, L.Y.; Duboc-Toia, C.; Ménage, S.; Riesgo, E. C.; Thummel, R. P.; New J. Chem. 1999, 23, 939. 